\title{
BIBLIOTHERAPY SEBAGAI SEBUAH TEKNIK DALAM LAYANAN BIMBINGAN DAN KONSELING
}

\section{(Bibliotherapy as a Technique in the Activities of Guidance and Counseling Services)}

\author{
ASEP SOLIKIN \\ Dosen Program Studi Bimbingan dan Konseling Fakultas Keguruan dan Ilmu Pendidikan \\ Universitas Muhammadiyah Palangkaraya.
}

\begin{abstract}
Bibliotherapy as a technique in the activities of guidance and counseling services at the moment is becoming a necessity in the world where both readings based information in the form of digital print out or have been so familiar with the people who are also experiencing problems in the individual development of their social life. Bibliotherapy often referred to reading theraphy, which is in the process someone who is having problems asked to read books that are helping themselves and motivate in order to promote healing. Read about the difficulties others similar to them, can provide awareness and understanding of the problems faced.

This research use descriptive approach or describing a problem based on literature review of existing literature or books in accordance with the guidelines of this study. In the implementation of this paper focuses on the study of literature study using historical study (Dirasat al - Tarikhiyah), which is trying to trace the concepts biblioteraphy, through studies and sources of books on therapy that are relevant to the discussion of this study .

Reading activities in bibliotherapy uses age-appropriate books in the treatment and therapy is usually followed by discussions on the topic of life issues in accordance with the experienced conditions. Bibliotherapy is used by school counselors, social workers, health nurses, teachers and librarians. The use of the book as a therapy to support the needs of children in the process information to increase understanding and raise awareness of the problems experienced.
\end{abstract}

Keywords: bibliotherapy, guidance and counseling

\begin{abstract}
ABSTRAK
Bibliotherapy sebagai sebuah teknik dalam kegiatan layanan bimbingan dan konseling pada saat ini sedang menjadi sebuah kebutuhan di mana dunia informasi berbasis bacaan baik yang berbentuk print out maupun digital telah begitu akrab dengan masyarakat yang juga mengalami permasalahan perkembangan individual dalam kehidupan bermasyarakat mereka. Bibliotherapy sering disebut juga terapi membaca, yang didalam prosesnya seseorang yang mengalami masalah diminta membaca buku-buku yang bersifat membantu dirinya dan memotivasi agar mempercepat penyembuhan. Membaca mengenai kesulitan orang lain yang sama dengan mereka, dapat memberikan kesadaran dan pemahaman terhadap masalah yang dihadapinya.

Penelitian ini menggunakan pendekatan deskripsif atau menggambarkan suatu masalah berdasarkan kajian pustaka yang telah ada pada literatur atau buku-buku panduan yang sesuai dengan kajian ini. Dalam pelaksanaan kajian penulisan ini memfokuskan pada studi kepustakaan dengan menggunakan study historis (dirasat al-Tarikhiyah), yakni berusaha menelusuri konsep-konsep biblioteraphy, melalui kajiankajian dan sumber-sumber buku-buku tentang terapi yang relevan dengan pembahasan kajian ini.

Aktivitas membaca dalam bibliotherapy menggunakan buku yang sesuai dengan usia dalam terapi pengobatan dan biasanya dilanjutkan dengan diskusi sesuai dengan topik masalah kehidupan yang sesuai dengan kondisi yang dialami. Bibliotherapy digunakan oleh konselor sekolah, pekerja sosial, perawat kesehatan, guru dan pustakawan. Penggunaan buku sebagai terapi untuk mendukung kebutuhan anak dalam memproses informasi untuk meningkatkan pemahaman dan meningkatkan kesadaran dalam masalah yang dialami.
\end{abstract}

Kata kunci: bibliotherapy, bimbingan dan konseling 


\section{PENDAHULUAN}

Ada banyak hal yang menjadi kajian dalam studi isu-isu global dan perkembangan muktahir bimbingan dan konseling. Setidaknya ada beberapa hal yang menjadi isu sentral yaitu: Landasan Bimbiungan dan Konseling, Alur pikir dan penegasan profesi konselor, Konselor: pribadi dan profesinya, Reposisi dan rekonseptualisasi:Komprehensive approach, Bimbingan konseling yang memandirikan, Terapi yang efektif terhadap individu, Manusia dan kebudayaan, Kesehatan manusia, Etika dan profesionalisme BK, Competence conection in global isues

Namun dari kesemua hal terebut ada hal yang mendapat perhatian penting dalam review ini sebagai isu yang perlu mendapat sorotan lebih yaitu konselor pendidikan sebagai pribadi dan profesinya. Dasar pemikiran penyelenggaraan bimbingan dan konseling di Sekolah/Madrasah, bukan semata-mata terletak pada ada atau tidak adanya landasan hukum (perundang-undangan) atau ketentuan dari atas, namun yang lebih penting adalah menyangkut upaya memfasilitasi peserta didik yang selanjutnya disebut konseli, agar mampu mengembangkan potensi dirinya atau mencapai tugas-tugas perkembangannya (menyangkut aspek fisik, emosi, intelektual, sosial, dan moral-spiritual).

Konseli sebagai seorang individu yang sedang berada dalam proses berkembang atau menjadi (on becoming), yaitu berkembang ke arah kematangan atau kemandirian. Untuk mencapai kematangan tersebut, konseli memerlukan bimbingan karena mereka masih kurang memiliki pemahaman atau wawasan tentang dirinya dan lingkungannya, juga pengalaman dalam menentukan arah kehidupannya. Disamping itu terdapat suatu keniscayaan bahwa proses perkembangan konseli tidak selalu berlangsung secara mulus, atau bebas dari masalah. Dengan kata lain, proses perkembangan itu tidak selalu berjalan dalam alur linier, lurus, atau searah dengan potensi, harapan dan nilai-nilai yang dianut.

Perkembangan konseli tidak lepas dari pengaruh lingkungan, baik fisik, psikis maupun sosial. Sifat yang melekat pada lingkungan adalah perubahan. Perubahan yang terjadi dalam lingkungan dapat mempengaruhi gaya hidup (life style) warga masyarakat. Apabila perubahan yang terjadi itu sulit diprediksi, atau di luar jangkauan kemampuan, maka akan melahirkan kesenjangan perkembangan perilaku konseli, seperti terjadinya stagnasi (kemandegan) perkembangan, masalahmasalah pribadi atau penyimpangan perilaku. Perubahan lingkungan yang diduga mempengaruhi gaya hidup, dan kesenjangan perkembangan tersebut, di antaranya: pertumbuhan jumlah penduduk yang cepat, pertumbuhan kota-kota, kesenjangan tingkat sosial ekonomi masyarakat, revolusi teknologi informasi, pergeseran fungsi atau struktur keluarga, dan perubahan struktur masyarakat dari agraris ke industri.

Iklim lingkungan kehidupan yang kurang sehat, seperti : maraknya tayangan pornografi di televisi dan VCD; penyalahgunaan alat kontrasepsi, minuman keras, dan obat-obat terlarang/narkoba yang tak terkontrol; ketidak harmonisan dalam kehidupan keluarga; dan dekadensi moral orang dewasa sangat mempengaruhi pola perilaku atau gaya hidup konseli (terutama pada usia remaja) yang 
cenderung menyimpang dari kaidah-kaidah moral (akhlak yang mulia), seperti: pelanggaran tata tertib Sekolah/Madrasah, tawuran, meminum minuman keras, menjadi pecandu Narkoba atau NAPZA (Narkotika, Psikotropika, dan Zat Adiktif lainnya, seperti: ganja, narkotika, ectasy, putau, dan sabu-sabu), kriminalitas, dan pergaulan bebas (free sex).

Penampilan perilaku remaja seperti di atas sangat tidak diharapkan, karena tidak sesuai dengan sosok pribadi manusia Indonesia yang dicita-citakan, seperti tercantum dalam tujuan pendidikan nasional (UU No. 20 Tahun 2003), yaitu: (1) beriman dan bertaqwa terhadap Tuhan Yang Maha Esa, (2) berakhlak mulia, (3) memiliki pengetahuan dan keterampilan, (4) memiliki kesehatan jasmani dan rohani, (5) memiliki kepribadian yang mantap dan mandiri, serta (6) memiliki rasa tanggung jawab kemasyarakatan dan kebangsaan. Tujuan tersebut mempunyai implikasi imperatif (yang mengharuskan) bagi semua tingkat satuan pendidikan untuk senantiasa memantapkan proses pendidikannya secara bermutu ke arah pencapaian tujuan pendidikan tersebut.

Upaya menangkal dan mencegah perilakuperilaku yang tidak diharapkan seperti disebutkan, adalah mengembangkan potensi konseli dan memfasilitasi mereka secara sistematik dan terprogram untuk mencapai standar kompetensi kemandirian. Upaya ini merupakan wilayah garapan bimbingan dan konseling yang harus dilakukan secara proaktif dan berbasis data tentang perkembangan konseli beserta berbagai faktor yang mempengaruhinya.
Dengan demikian, pendidikan yang bermutu, efektif atau ideal adalah yang mengintegrasikan tiga bidang kegiatan utamanya secara sinergi, yaitu bidang administratif dan kepemimpinan, bidang instruksional atau kurikuler, dan bidang bimbingan dan konseling. Pendidikan yang hanya melaksanakan bidang administratif dan instruksional dengan mengabaikan bidang bimbingan dan konseling, hanya akan menghasilkan konseli yang pintar dan terampil dalam aspek akademik, tetapi kurang memiliki kemampuan atau kematangan dalam aspek kepribadian.

Atas dasar itu, maka implementasi bimbingan dan konseling di Sekolah/Madrasah diorientasikan kepada upaya memfasilitasi perkembangan potensi konseli, yang meliputi aspek pribadi, sosial, belajar, dan karir; atau terkait dengan pengembangan pribadi konseli sebagai makhluk yang berdimensi biopsikososiospiritual (biologis, psikis, sosial, dan spiritual).

Layanan bimbingan dan konseling merupakan bagian integral dari pendidikan di Indonesia. Sebagai sebuah layanan profesional, kegiatan layanan bimbingan dan konseling tidak bisa dilakukan secara sembarangan, namun harus berangkat dan berpijak dari suatu landasan yang kokoh, yang didasarkan pada hasil-hasil pemikiran dan penelitian yang mendalam. Dengan adanya pijakan yang jelas dan kokoh diharapkan pengembangan layanan bimbingan dan konseling, baik dalam tataran teoritik maupun praktek, dapat semakin lebih mantap dan bisa dipertanggungjawabkan serta mampu memberikan manfaat besar bagi kehidupan, khususnya bagi para penerima jasa layanan (klien). 
Agar aktivitas dalam layanan bimbingan dan konseling tidak terjebak dalam berbagai bentuk penyimpangan yang dapat merugikan semua pihak, khususnya pihak para penerima jasa layanan (klien) maka pemahaman dan penguasaan tentang landasan bimbingan dan konseling khususnya oleh para konselor tampaknya tidak bisa ditawar-tawar lagi dan menjadi mutlak adanya.

Berbagai kesalahkaprahan dan kasus malpraktek yang terjadi dalam layanan bimbingan dan konseling selama ini,-- seperti adanya anggapan bimbingan dan konseling sebagai "polisi sekolah", atau berbagai persepsi lainnya yang keliru tentang layanan bimbingan dan konseling,- sangat mungkin memiliki keterkaitan erat dengan tingkat pemahaman dan penguasaan konselor tentang landasan bimbingan dan konseling. Dengan kata lain, penyelenggaraan bimbingan dan konseling dilakukan secara asalasalan, tidak dibangun di atas landasan yang seharusnya.

Bibliotherapy sebagai sebuah teknik dalam kegiatan layanan bimbingan dan konseling pada saat ini sedang menjadi sebuah kebutuhan di mana dunia informasi berbasis bacaan baik yang berbentuk print out maupun digital telah begtu akrab dengan masyarakat yang juga mengalami permasalahan perkembangan individual dalam kehidupan bermasyarakat mereka.

\section{METODOLOGI}

Penelitian ini menggunakan pendekatan deskripsif atau menggambarkan suatu masalah berdasarkan kajian pustaka yang telah ada pada literatur atau buku-buku panduan yang sesuai dengan kajian ini. Dalam pelaksanaan kajian penulisan ini memfokuskan pada studi kepustakaan dengan menggunakan study historis (dirasat al-Tarikhiyah), yakni berusaha menelusuri konsep-konsep biblioteraphy, melalui kajian-kajian dan sumber-sumber buku-buku tentang terapi yang relevan dengan pembahasan kajian ini. Selain itu. Penulis juga memantau fenomena global yang terjadi di dalam masyarakat dewasa ini, yang kemudian dilakukan analisis perbandingan antara teori dan praktek yang sesuai dan yang tidak sesuai dengan terapi yang sedang dikaji, beserta dampak yang ditimbulkannya.

Selain pendekatan di atas dan berdasar pada judul yang dibahas, maka pendekatan lain yang digunakanoleh penulis adalah sebagai berikut :

a. Pedekatan Paedagogik, yaitu metode pendekatan yang didasarkan kepada ilmuilmu pendidikan, khususnya yang berkaitan teknik serta terapi yang dapat digunakan dalam dunia pendidikan

b. Pendekatan Psikologis, yaitu suatu hal yang didasarkan pada ilmu-ilmu yang mempelajari tentang kejiwaan manusia.

c. Pendekatan Bimbingan dan Konsleing, yaitu menjadikan teknik ini sebagai bagian yang menjadi khazanah ilmu pegetahuan dalam dunia bimbingan dan konseling.

\section{HASIL DAN PEMBAHASAN}

\section{Konsep Bibliotherapy dalam Bimbingan dan Konseling}

Istilah bibliotherapy berasal dari bahasa Yunani, yaitu biblus berarti buku, dan therapy yaitu upaya bantuan psikologis, oleh karena itu bibliotherapy dapat didefinisikan sebagai 
penggunaan buku-buku untuk membantu memecahkan masalah. Menurut Eva Imania Eliasa (dalam Bibliotherapy As A Method of Meaningful Treatment. ISSN 114 434-438) Bibliotherapy merupakan sebuah terapi ekspresif yang didalamnya terdapat hubungan individu dengan isi atau intisari buku, puisi dan tulisan lain sebagai sebuah terapi.

Menurut Pardeck (dalam Nabila Chairani. 2015 Potensi Bibliotherapy dalam mengurangi kecemasan akibat hospitallisasi pada anak usia sekolah. ISSN 2338-4700) "Bibliotherapy adalah penatalaksanaan kesehatan mental dengan menggunakan buku untuk membantu meningkatkan koping anak terhadap perubahan, masalah emosional dan mental". Dalam biblioterapi interaktif, fasilitator yang terlatih menggunakan diskusi terarah untuk membantu klien mengintegrasikan respons kognitif dan perasaan terhadap literatur yang telah diseleksi.

Bibliotherapy sering disebut juga terapi membaca, yang didalam prosesnya seseorang yang mengalami masalah diminta membaca buku-buku yang bersifat membantu dirinya dan memotivasi agar mempercepat penyembuhan. Membaca mengenai kesulitan orang lain yang sama dengan mereka, dapat memberikan kesadaran dan pemahaman terhadap masalah yang dihadapinya.

Aktivitas membaca dalam bibliotherapy menggunakan buku yang sesuai dengan usia dalam terapi pengobatan dan biasanya dilanjutkan dengan diskusi sesuai dengan topik masalah kehidupan yang sesuai dengan kondisi yang dialami. Bibliotherapy digunakan oleh konselor sekolah, pekerja sosial, perawat kesehatan, guru dan pustakawan. Penggunaan buku sebagai terapi untuk mendukung kebutuhan anak dalam memproses informasi untuk meningkatkan pemahaman dan meningkatkan kesadaran dalam masalah yang dialami. Dengan membaca buku atau mengeksplorasi sumbersumber baru dari internet, anak dapat mengekspresikan perasaanya.

Menurut Shechtman (2009) (dalam Eva Imania Eliasa Bibliotherapy As A Method of Meaningful Treatment. ISSN 114 434-438) menekankan bahwa "Bibliotherapyentails the use of literature for therapeutic purposes and it includes listening to storiesand poems, watching films, and looking at pictures. It is a playful, engaging, and fun process." Shechtman mengkombinasikan kegiatan mendengarkan cerita, membaca puisi,menonton film dan gambar dilakukan didalam rangkaian bibliotherapy, sehingga aktivitas berjalan menarik dan menyenangkan.

Terapi pustaka ini mencakup tugas membaca terhadap bahan bacaan yang terseleksi, terencana, dan terarah sebagai suatu prosedur treatment atau tindakan dengan tujuan penyembuhan karena diyakini bahwa pembaca dapat mempengaruhi sikap, perasaan, dan perilaku individu sesuai dengan yang diharapkan. Penggunaan terapi pustaka sebagai salah satu alternatif terapi dalam menangani berbagai permasalahan pada remaja yang perlu dipertimbangkan. Hal ini disebabkan karena bibliotherapy dapat merangsang remaja untuk berfikir, mudah, murah, dan dapat dilakukan kapan saja serta melibatkan kemandirian dan partisipasi remaja sendiri secara penuh sehingga efektivitas hasilnya cukup baik (Eliasa. 
Bibliotherapy As A Method of Meaningful Treatment. ISSN 114 434-4382007).

Pada bibliotherapy, diskusi sederhana setelah membaca dapat membantu menyelesaikan permasalahan anak. Anak usia sekolah yang telah memilki kemampuan menulis dan membaca buku dengan baik, memungkinkan anak dapat memanfaatkan buku untuk memahami pengalamannya dan mengekspresikan perasaan melalui membaca dan menulis untuk membantu mengingkatkan pemahaman anak/peserta didik.

Bibliotherapy menjadi media untuk membantu konseli dalam mengatasi masalah pribadinya. Dalam sebuah proses bibliotherapy interaktif, setidaknya lebih dari satu orang, biasanya profesional guru atau lainnya, memfasilitasi keterlibatan peserta. Bibliotherapy yang dilakukan secara interaktif menekankan perkembangan pertumbuhan pengembangan diri, tidak hanya dalam intervensi klinis saja (misalnya, penggunaan bibliotherapy dalam pengaturan seperti unit kejiwaan, pusat kesehatan mental masyarakat, dan program ketergantungan kimia). Bibliotherpy interaktif menekankan proses interaktif antara anggotanya, dan biasanya seorang guru atau profesional lain memfasilitasi keterlibatan peserta melalui materi tertulis dan kegiatan terkait seperti diskusi kelompok.

\section{Fungsi Bibliotherapy}

Menurut Nola Kortner (dalam Eva Imania Eliasa Bibliotherapy As A Method of Meaningful Treatment. ISSN 114 434-438) fungsi bibliotherapy dapat diambil dengan latar belakang masalah:

a) Untuk mengembangkan sebuah self-concept individu b) Untuk meningkatkan pemahaman tingkah laku atau motivasi diri

c) Untuk membentuk kejujuran diri

d) Untuk menunjukkan jalan menemukan jati diri dan minat lain

e) Untuk ketahanan emosi dan tekanan mental

f) Untuk menunjukan bahwa dia bukan satusatunya orang yang mempunyai masalah

g) Untuk menunjukkan bahwa lebih dari satu dalam pemecahan masalah

h) Untuk menolong seseorang dengan diskusi masalah

i) Untuk membantu merencanakan sebuah langkah kerja dalam menyelesaikan masalah.

\section{Tujuan}

Tujuan bibliotherapy (http://shifa-idhasalsabila.blogspot.com.22 April 2015 ) pada dasarnya sama dengan tujuan bimbingan yaitu:

a) Membantu para anggota agar dapat membantu dirinya sendiri.

b) Menyajikan informasi yang dibutuhkan atau sesuai dengan nilai karakter yang ingin mereka bangun.

c) Membentuk tingkah lakunya secara umum, dengan mêngetahui informasi yang ada dalam bahan bacaan, mereka dapat secara khusus membentuk sikap, persepsi, mengubah prasangka sosial dan perubahan lainnya.

d) Mendampingi seseorang yang tengah mengalami emosional yang berkecamuk karena permasalahan yang dihadapi dengan menyediakan bahan-bahan bacaan dengan topik yang tepat dan mengandung nilai-nilai 
karakter yang ingin dibangun pada din individu yang bersangkutan.

e) Sebagai stimulasi pikiran yang memungkinkan para anggota dapat menyilangkan gagasan-gagasan sehingga kesadarannya menjadi meningkat.

\section{Prosedur Bibliotherapy}

Menurut Nabila Chairani (dalam jurnal Potensi Bibliotherapy dalam mengurangi kecemasan akibat hospitallisasi pada anak usia sekolah. ISSN 2338-4700) Bibliotherapy terdiri dari tiga tahapan yaitu identifikasi, katartis, dan wawasan mendalam (insight). Penjelasan dari masing-masing tahapan tersebut adalah sebagai berikut:

1. Identifikasi

Anak mengidentifikasi dirinya dengan karakter dan peristiwa yang ada dalam buku, baik yang bersifat nyata maupun fiktif. Bila bahan bacaan yang disarankan tepat, maka klien akan mendapatkan karakter yang mirip atau mengalami peristiwa yang sama dengan dirinya. Digunakan buku yang sesuai dengan tahapan perkembangan usia anak dan mirip dengan situasi yang dialami anak.

2. Katartis

Pertama-tama pembaca mengikuti tantangan atau masalah karakter, dan kemudian membaca bagaimana situasi ini diselesaikan. Setelah situasi teratasi, pengalaman rasa lega terjadi. Anak menjadi terlibat secara emosional dalam kisah dan menyalurkan emosi yang terpendam dalam dirinya (melalui diskusi atau karya seni). Selain itu, pembaca juga dapat mengidentifikasi dirinya dengan emosi karakter. Akibatnya, para pembaca menunjukkan emosi mereka dalam tahap ini. Selain diikuti dengan diskusi, memungkinkan bagi anak yang sulit mengungkapkan perasaannya secara verbal menggunakan cara lain yaitu melalui tulisan, mewarnai, menggambar, drama dengan menggunakan boneka atau bermain peran.

3. Wawasan mendalam (insight)

Anak menyadari bahwa masalah yang mereka hadapi bisa diselesaikan. Permasalahan anak mungkin saja ditemukan dalam karakter tokoh dalam buku sehingga dalam menyelesaikan masalah dengan mempertimbangkan langkahlangkah yang ada dalam cerita. Aplikasi bibliotherapy dilakukan dengan cara:

a) Mengidentifikasi kebutuhan anak yang dilakukan melalui pengamatan.

b) Menyesuaikan kebutuhan anak dengan bahan bacaan yang tepat.

c) Memutuskan susunan waktu, sesi, serta bagaiman sesi diperkenalkan pada anak.

d) Merancang aktivitas tindak lanjut setelah membaca seperti diskusi, menulis, menggambar atau drama.

e) Memotivasi anak dengan aktivitas pengenalan seperti mengajukan pertanyaan-pertanyaan pokok dan mulai berdiskusi tentang bacaan. Secara berkala, simpulkan apa yang terjadi secara detail.

f) Memberi jeda waktu beberapa menit agar anak dapat merefleksikan materi bacaannya.

g) Mendampingi anak mengakhiri terapi melalui diskusi dan menyusun daftar jalan keluar yang mungkin atau aktivitas lainnya. 


\section{KESIMPULAN DAN SARAN}

a. Bibliotherapy sering disebut juga terapi membaca, yang didalam prosesnya seseorang yang mengalami masalah diminta membaca buku-buku yang bersifat membantu dirinya dan memotivasi agar mempercepat penyembuhan.

b. Membaca mengenai kesulitan orang lain yang sama dengan mereka, dapat memberikan kesadaran dan pemahaman terhadap masalah yang dihadapinya.

c. Dalam prinsip-prinsip implementasinya, bibliotherapy harus memperhatikan konsepkonsep, fungsi, tujuan dan prosedurnya.

d. Esensi Bibliotherapy menjadi media untuk membantu konseli dalam mengatasi masalah pribadinya yang dilakukan secara interaktif menekankan perkembangan pertumbuhan pengembangan diri, tidak hanya dalam intervensi klinis saja (misalnya, penggunaan bibliotherapy dalam pengaturan seperti unit kejiwaan, pusat kesehatan mental masyarakat, dan program ketergantungan kimia).

\section{DAFTAR PUSTAKA}

Aqib, Zainal. 2013. Konseling Kesehatan Mental. Bandung: Yrama Widya.

Ali, Mohammad \& Asrori, Muhammad. 2010. Psikologi Remaja. Jakarta: Bumi Aksara.

Alwisol. 2014. Psikologi Kepribadian. Malang: UMM Press.

Corey, Gerald. 2013. Teori Dan Praktek Konseling Dan Psikoterapi. Diterjemahkan oleh E.Koswara. Bandung: Refika Aditama.
Countur Rony. 2007. Metode Penelitian. Jakarta: PPM.

Eliasa\& iswanti. 2014. Bibliotherapy With The Career Topic To Increase The Student's Career Motivation of Guidance And Counseling. Procedia - Social and Behavioral Sciences.

Efriani, Rida. 3 Februari 2015. Pelajar Bolos Bawa Rokok Hingga Obeng. http://manado.tribunnews.com.

Feist, Jess \& Feist J, Gregory. 2010. Teori Kepribadian. Jakarta: Salemba Humanika

Fatimah, Enung. 2006. Psikologi perkembangan. Bandung: Pustaka setia.

Gibson L Robert \& Mitchell H Marianne, 2011. Bimbingan dan Konseling. Diterjemahkan oleh Santoso Yudi. Yogyakarta: Pustaka Pelajar.

Ningsih, Nurnia. 2011. Bimbingan Kelompok Untuk Meningkatkan Kecerdasan Emosional Siswa. Jurnal Penelitian.ISSN 1412-565X

Rafikasari, Diana. 22 Februari 2015. Perokok Remaja di Indonesia Makin Bertambah. http://lifestyle.sindonews.com

Sugiyono. 2013. Metode Penelitian Pendidikan Pendekatan Kuantitatif, Kualitatif, dan $R \& D$. Bandung. CV Alfabeta.

Willis, Sofyan. 2013. Konseling Individual Teori dan Praktek. Bandung. CV Alfabeta.

Wahidin dkk. 2012. Pemahaman Remaja Tentang Kenakalan Dan Partisipasi Masyarakat Dalam Mengatasi Kenakalan Remaja Di Kecamatan Mamajang Makassar. ISSN 2302-6340. 